\title{
Postneoliberalismo y policía: caso de Ecuador 2007-2013
}

\author{
DANIEl PONTÓN* \\ FREDY RIVERA VÉLEZ ${ }^{* *}$
}

Artículo recibido: 30 de agosto de 2015

Artículo aceptado: 15 de abril de 2016

Doi: http://dx.doi.org/10.12804/desafios28.2.2016.06

Para citar este artículo: Pontón, D. \& Rivera, F. (2016). Postneoliberalismo y policía: caso de Ecuador 2007-2013. Desafíos, 28(2): 213-253. Doi: http://dx.doi.org/10.12804/desafios28.2.2016.06

\section{Resumen}

La administración presidencial de Rafael Correa, iniciada en el 2007, forma parte de la tendencia politica post-neoliberal que presentan algunos países de la región. En materia de política pública, este gobierno se planteó como desafío transformar y modernizar la Policía Nacional como parte de un nuevo modelo de seguridad integral. ¿Qué cambios estructurales ha experimentado la cuestión policial en el Ecuador? ¿Qué explica y qué razonamiento político está asociado con estos cambios? La presente investigación analizará el ámbito policial y su proceso de cambios, continuidades y retrocesos en el periodo 2007-2013. Se argumentará que pese a existir avances en la transformación de la policía, estos no se enmarcan bajo una orientación programática de una reforma institucional democrática de la policía. Por el contrario, los cambios han obedecido a lógicas de aprendizaje propias del pragmatismo politico en el ejercicio del poder y las racionalidades del gobierno contra el delito. La ausencia de esta agenda programática ha dado paso a un proceso de colonización policial en

* Master en Política Pública. Doctorando en Sociología por la Universidad Nacional del Cuyo, Mendoza-Argentina. Docente del Centro de Seguridad y Defensa del Instituto de Altos Estudios Nacionales I.A.E.N, Quito. Correo electrónico: daniel.ponton@iaen.edu.ec ** Doctor en Ciencias Sociales. Coordinador del Departamento y Doctorado en Estudios Internacionales, FLACSO Sede Ecuador, Director de la Revista Latinoamericana de Estudios de Seguridad -URVIO-. Correo electrónico: frivera@flacso.edu.ec 
la compresión y conducción politica de la institución policial, lo cual ha generado que las reformas iniciadas reproduzcan estructuras tradicionales y corporativas.

Palabras clave: postneoliberalismo, policía, reforma, cambios, continuidades.

\title{
Post-Neoliberalism and Police: The Case of Ecuador 2007-2013
}

\begin{abstract}
The administration of President Rafael Correa, which started in 2007 in Ecuador, is part of the post-neoliberal political trend shared by some countries in the Latin American region. In terms of public policy it was conceived as a challenge to transform and modernize the National Police as part of a new model of an integral security system. What structural changes have the police experienced in Ecuador? What political reasoning has been associated with these changes? This article analyzes the changes, continuities and setbacks in the National Police institution from 2007 to 2013. We argue that although there has been progress in the transformation of the police, the key to understand the changes is not within the democratic police reform framework. By contrast, the changes have been part of the typical political pragmatism in the exercise of power and the government rationalities in the fight against crime. The combination of these factors has led to a process of "police-perspective colonization" in understanding and governing the police, which meant that the reforms reproduce traditional corporate structures.
\end{abstract}

Keywords: Post-neoliberalism, police reform, changes, continuities.

\section{Posneoliberalismo e policía: Caso de Equador 2007-2013}

\section{Resumo}

A administração presidencial de Rafael Correa, iniciado em 2007, é parte da tendência política pós-neoliberal exibido por alguns países da região. Em política pública foi criado como um desafio, para transformar e modernizar a Polícia Nacional como parte de um novo modelo de segurança abrangente. Que mudanças estruturais ha experimentado a questão da polícia no Equador? O que explica e o que razão política está associada a essas mudanças? Esta pesquisa deve analisar policiamento 
e processar mudanças, continuidades e reversões no período de 2007-2013. Será argumentado que, embora haja progresso na transformação da policia, não caem sob uma orientação programática de uma reforma institucional democrática da polícia. Pelo contrário, as mudanças têm obedecido à própria lógica de pragmatismo político no exercício da lógica do poder e do governo contra o aprendizado crime. A ausência desta agenda programática, deu lugar a um processo de compressão polícia colonização e política da direção da polícia, o que tem gerado as reformas e reproduzir estruturas corporativas tradicionais.

Palavras- chave: Postneoliberalism, reforma da polícia, mudanças, continuidades.

\section{Introducción}

El gobierno de la revolución ciudadana del presidente Rafael Correa se planteó desde el año 2007 el desafío de lograr una profunda transformación social, económica y política del país. Inmersa en los lineamientos ideológicos de la nueva izquierda Latinoamericana, crítica y lejana de las visiones neoliberales y neoconservadoras puestas en marcha en la región desde los años ochenta y noventa, la política pública ecuatoriana adoptó tempranamente estrategias para trasformar, fortalecer y reposicionar al Estado nacional.

En ese contexto, desde la década de los ochenta, el debate sobre la reforma policial, sus orgánicos funcionales y la vinculación con la comunidad, se han constituido en tema central y tendencia generalizada en la región. Varias son las definiciones y aportes sobre reforma policial en la región (Saín, 2009; Frühling, 2002) que incorporan temas de debate público vinculados con cambios doctrinarios, eficacia institucional, democratización y rendición de cuentas, y que conducen a la necesidad histórica de transformar viejas estructuras policiales anquilosadas en prácticas autoritarias, corruptas y violadoras de derechos humanos, muchas de ellas producto de la influencia de la doctrina de seguridad nacional (Rivera, 2011). A pesar de esta realidad, no existió una verdadera reforma policial desde el retorno democrático en 1979 hasta el año 2007, cuando asumió la presidencia Rafael Correa (Pontón, 2007, 2009). 
Por esta razón, vale la pena preguntarnos: ¿han existido cambios estructurales importantes en la Policía Nacional del Ecuador en estos siete años de gobierno? Si es así, ¿cuáles son los cambios o rupturas más importantes? ¿Qué continuidades o inercias institucionales se mantienen? ¿Cuáles son sus características? El presente artículo analizará el ámbito policial en Ecuador y su proceso de cambio en el periodo presidencial de Rafael Correa. Se argumentará que pese a existir avances en la transformación del campo policial en este periodo gubernamental, estas modificaciones obedecen más bien a influencias de la reforma del Estado más que a un interés programático en el campo policial. Esto ha conducido a que las reformas alcanzadas sean discontinuas, poco integrales y se mantengan estructuras tradicionales que se adaptan más a lógicas del pragmatismo político y de control social.

Este artículo asumirá enfoques neoinstitucionales. Tradicionalmente, las reformas institucionales parten de la creencia de que las modificaciones al sistema jurídico, orgánico y administrativo sentarán las bases formales para un nuevo o reformado tipo de Estado. En el desarrollo contemporáneo de las ciencias sociales y políticas, las instituciones han perdido su posición central en los análisis sociales. Actualmente, los esfuerzos teóricos se han dirigido a la compresión de los contextos y los actores, ${ }^{1}$ que se constituyen en la base sobre la cual se entienden los procesos sociales (Almond, Flanagan \& Mundt, 1993). De esta forma, es necesario mirar más allá de las instituciones y de las estructuras organizacionales y fijarse en los comportamientos de los actores y los contextos para tener una lectura más plena de los problemas (March \& Olsen, 1993).

Por esta razón, el artículo se fijará en analizar la conducción política de la cuestión policial en Ecuador. Es importante mencionar este detalle, porque el desempeño policial estaba cargado de autogobierno y espíritu corporativo, y se encontraba distanciado de la injerencia civil

\footnotetext{
1 Los contextos pueden ser sociales, políticos, económicos. Los actores, por su parte, pueden ser agentes o individuos de elección más o menos racional; así como clases, movimientos u organizaciones sociales.
} 
en el escrutinio púbico. De esta manera, para entender los procesos de reforma o no reforma policial, se debe comprender los incentivos o desincentivos de los actores políticos del Ecuador en un contexto de transformación estatal y amplia concentración de poder gubernamental como ha sido el gobierno de Rafael Correa desde el año 2007.

Este trabajo estará dividido en tres secciones. En la primera se denominará el contexto donde se analizará la conducción de la policía desde 1979, los lineamientos políticos del gobierno de Rafael Correa y los primeros tres años de gestión gubernamental, marcada por un alto nivel de conflictividad en la temática. La segunda parte analizará el impacto del 30 de septiembre 2010 en las motivaciones políticas de cambio estructural de la Policía Nacional, que incluye el estudio de la reforma legal e institucional, la desconcentración policial y las políticas de control del delito. Luego se analizarán los alcances de las reformas en áreas puntuales de la policía como la investigación criminal, la política de bienestar policial y el proceso de controles internos y externos.

\section{La Policía Nacional del Ecuador en la era democrática ${ }^{2}$}

Con el retorno democrático en el año 1979 no se vislumbraron transformaciones fundamentales en la estructura institucional de la Policía Nacional. Hasta la actualidad es un órgano estatal centralizado y único, de naturaleza civil, cuyo representante máximo, el Comandante General, es nombrado directamente por el Presidente de la República. Las Constituciones Políticas de 1979 y de 1998 mantuvieron la estructura castrense y la imagen militar asociada a la doctrina de seguridad nacional. Según la Ley Orgánica de la Policía Nacional de 1998, aún vigente, esta es una institución profesional y técnica organizada bajo el sistema jerárquico disciplinario. Los títulos de oficiales, así como los valores que orientan la institución son militares. ${ }^{3}$

\footnotetext{
2 Nos referiremos a este periodo por cuestiones argumentativas a los años comprendidos entre 1979 y 2007.

3 En la Constitución de 1979 se definía que el fin primordial de la Fuerza Pública, llámense
} 
Ahora bien, el contexto que circunscribió el accionar policial durante el regreso a la democracia estuvo marcado por recurrentes crisis económicas, asociadas a los altos intereses de la deuda externa y a las caídas abruptas del precio del petróleo, principal producto de exportación y sostén de la economía nacional; esto trajo consigo en el accionar policial cuatro elementos importantes:

1) Al igual que otros sectores del Estado, y aupado por una ideología que promovía el recorte del gasto público, la policía fue afectada en su desempeño institucional, una suerte de proceso sistemático de lumpenización que repercutió gravemente la credibilidad ante la ciudadanía. Por ejemplo, en el año 2005, según la encuesta ENACPOL, la Policía Nacional fue, junto a la Función Judicial, una de las instituciones peor percibidas y evaluadas del país, debido al desprestigio surgido por la corrupción. Por su parte, según Corporación Latinobarómetro (2004) la Policía del Ecuador era percibida por la población como la tercera más corrupta a nivel de América Latina (Pontón, 2009).

2) La institución policial fue utilizada políticamente como un instrumento eficaz para reprimir movilizaciones populares y conflictos sociales desatados por las recurrentes crisis económicas. A partir del año 1997, período de elevada inestabilidad política, se observa una profunda relación entre politización de la conducción policial y una alta rotación de mandos superiores; por ejemplo, la duración en sus cargos de los Ministros de Gobierno y Comandantes de la Policía fue de un poco más de seis meses desde 1984 hasta 2007.

3) El periodo presidencial de León Febres Cordero (1984-1988) fue el más crítico por la intervención policial en actos de violación a los derechos humanos. A principio de los años noventa se suprimió el temido Servicio de Investigación Criminal -SIC $-^{4}$, unidad

militares o policías, era salvaguardar la soberanía nacional, la defensa, integralidad e independencia del Estado, y la garantía del orden jurídico. Por lo tanto, todavía se privilegiaba una visión militar de la seguridad destinada primordialmente a la defensa de la seguridad interna.

4 Con la abolición del Servicio de Investigación Criminal -SIC- se dio paso a la creación de la OID -Oficina de Investigación del Delito-. A partir de la Reforma Judicial del año 2000 se creó lo que hoy se conoce como Policía Judicial (PJ). 
inspirada en la doctrina de seguridad nacional y creada inorgánicamente a principio de los años ochenta para la lucha anti subversiva. Las acciones de esta unidad y el mando policial de aquella época están siendo juzgados en la actualidad.

4) Paralelamente, durante las décadas de los años ochenta y noventa, Ecuador empezó a experimentar un incremento constante de los índices de violencia y criminalidad, fenómenos asociados al deterioro estructural que sufrió América Latina en esas décadas. Así, la tasa de homicidios por cada 100.000 habitantes pasó de 6,4 en 1980 a 10,4 en 1990; en el año 1999, la tasa ascendió a 14,8 y a mediados de la década de 2000 se posicionó sobre los 16 puntos. De igual forma, se evidenció un importante crecimiento en la tasa de denuncias de delitos contra la propiedad, delitos considerados de mayor impacto en la percepción de inseguridad ciudadana que pasaron de 320 denuncias por cada 100.000 habitantes en el año 1995 a 471,5 en el año 1999 (Arcos, Carrión \& Palomeque, 2003). En el año 2007 la tasa fue de 515,78 denuncias (Policía Nacional del Ecuador, 2007).

Pese a estos hechos importantes, no se experimentaron cambios o reformas significativas en la institución policial para enfrentar los problemas de la criminalidad y la corrupción hasta el año 2007; aunque con la Constitución Política de 1998 se establecieron algunas condiciones jurídicas y políticas para la implementación de reformas, prácticamente la institucionalidad policial se mantuvo intacta (gráfico 1$).^{5}$

Con la Ley Orgánica de 1998, la Policía Nacional logró tener personería jurídica y autonomía administrativa-financiera, a pesar de ser una institución adscrita al Ministerio de Gobierno (actual Ministerio del Interior). Esta situación fue matizando el desempeño institucional

\footnotetext{
5 A pesar del crecimiento en los indicadores de criminalidad, la idea de El Ecuador es una isla de paz, desarrollada hasta finales de los años noventa, constituyó un imaginario contraproducente para las reformas policiales, porque escondió realidades delincuenciales y conflictos políticos y sociales internos. En otras palabras, a ausencia de necesidad o percepción de ella, ausencia de reformas.
} 


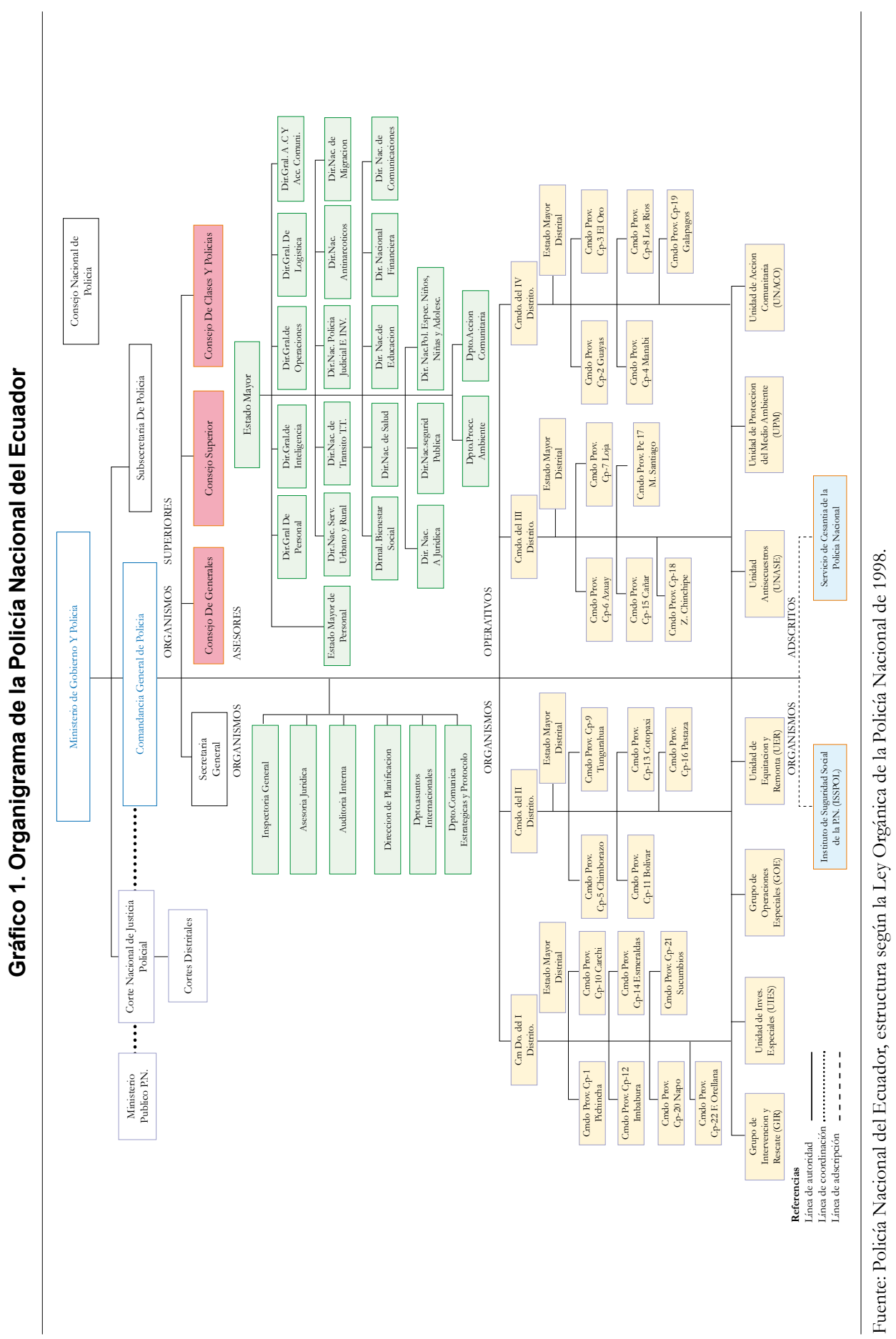


de la Policía durante los años posteriores. Por un lado, un abandono, desapego y desconocimiento del mando civil sobre el mundo policial, empleado para enfrentar la conflictividad social, y por otro lado, un autogobierno policial con carácter corporativo, que gestionó sus propios intereses en los procesos de fortalecimiento institucional.

Entre 1999 y 2000 se empezaron a evidenciar dos hechos que promovieron cambios importantes en la fisonomía de la seguridad pública y ciudadana del Ecuador. En primer lugar, las primeras movilizaciones y presiones populares en Quito y Guayaquil ante el crecimiento de ciertos tipos de delitos contra la propiedad y las personas que promovió la participación de los gobiernos locales en actividades que no eran de competencia municipal. Por otro lado, comenzaron a sentirse las consecuencias del Plan Colombia, que generó el aumento de ciertas actividades ilícitas y propició un imaginario de miedo y peligrosidad en la frontera norte del Ecuador.

Estos hechos generaron que el país empiece a desarrollar una política direccionada al aumento del control o lo que M. Sozzo (2005) denomina el lenguaje del déficit. Así, por un lado, se presenció un crecimiento considerable en el presupuesto de la seguridad pública que pasó de 134 millones de dólares en el año 2000 a cerca de 517 millones en el año 2007. El número de efectivos policiales eran 20.000 en los años 2000 y en el 2007 creció a cerca de 40.000 (Policía Nacional del Ecuador, 2015).

Si bien la modernización no fue propiamente una reforma institucional, aunque incorpore ciertas modificaciones de índole administrativa y operativa al interior de la institución, ${ }^{6}$ debe reconocerse como señal embrionaria de una nueva mirada y voluntad de cambio institucional interna que tuvo la Policía antes del 2007. Por esta razón, en 2004 la Policía Nacional, aprendiendo de otras experiencias similares en América Latina, lanzó el Plan Estratégico de Modernización y de

\footnotetext{
6 La reforma apunta a cambios estructurales a nivel macro de la institución, que no solo obedecen a la arquitectura organizacional, sino también a los cimientos culturales y doctrinarios.
} 
Transformación Integral 2004-2014. Esta iniciativa tuvo alcances limitados, ya que no contó con el necesario respaldo presupuestario y presentó muchos problemas en la ejecución final en cuanto a sus alcances de transformaciones legales, administrativas, financieras y procedimentales. En conclusión, desde el punto de vista neoinstitucional, este periodo estuvo marcado por una ausencia de voluntad política para ejercer cambios sustanciales en la Policía, y ciertas iniciativas truncadas desde el interior de la policía, que marcaron la orientación de la conducción institucional como veremos a continuación.

\section{Revolución ciudadana y reforma del Estado}

El ascenso de Rafael Correa al poder en el año 2007 significó poner fin a una etapa de inestabilidad política e ingobernabilidad que produjo la salida anticipada del poder de tres presidentes desde el retorno democrático. Este proceso político ha estado caracterizado por tener un altísimo respaldo popular en su proyecto político y por contar con alta concentración de poder. Esto le ha permitido ganar consecutivamente ocho elecciones desde 2006 entre los que se destacan tres elecciones presidenciales, tres consultas populares o referéndums, una elección de asambleístas y una elección de autoridades locales.

Los lineamientos políticos e ideológicos de este gobierno se orientan con la nueva izquierda Latinoamericana, que busca ser una alternativa a la influencia dominante de la política del Consenso de Washington de los ochenta y noventa. Las coordenadas del gobierno se han situado principalmente en la redefinición de una nueva política económica, basada en una reorientación de la política de pago de deuda externa y la prioridad en la inversión social, el endeudamiento público y soberano, la diminución de la dependencia, la integración regional, y la inversión en capital humano y social, es decir, una nueva mirada a la política de desarrollo nacional (Correa, 2005). En materia de política externa, se ha caracterizado también por tener una revisión profunda de la cooperación con Estados Unidos, sostener posiciones críticas frente los tratados de libre comercio con ese país, una posición adversa a las estrategias y resultados del Plan Colombia 
y el rescate de visiones soberanistas y de unidad nacional (Ramírez \& Minteguiaga, 2007).

Pero uno de los elementos más importantes de este proyecto político ha sido la recuperación del rol del Estado. Para ello, se fortaleció la planificación central del Estado, a través de la Secretaría Nacional de Planificación y Desarrollo (SENPLADES), que ha cumplido un rol fundamental en la racionalización del Estado, la coordinación y la previsión de la agenda pública (Ramirez \& Minteguiaga, 2007). En este escenario, el Estado ha sido conceptualizado como un elemento activo y vital para la estrategia de desarrollo nacional. El objetivo, según Muñoz (2012), ha sido incorporar reformas legales e institucionales para descorporativizar las entidades públicas y recuperar facultades como la rectoría, regulación y control de la política pública con amplio espíritu de redistribución equitativa de recursos y capacidades en el territorio. Son pilares también en esta recuperación del rol estatal, la descentralización y desconcentración del Estado, a través de un fuerte proceso de inversión pública, modernización y cambio de cultura en la atención de servicios.

Un elemento clave en este proceso político es sin duda la nueva Constitución de la República aprobada en el 2008. En el marco de la seguridad del Estado, la nueva Constitución plantea algunos aportes y avances, los mismos que han ido delineando los diferentes cuerpos normativos, políticas, planes y agendas de seguridad, que pretenden neutralizar los enfoques seguritarios y represivos por un enfoque de seguridad humana; asumir la soberanía como un principio que va más allá del aspecto territorial; cambios en la misión y visión de las fuerzas armadas y la policía, entre otros.

Otro asunto importante los constituye la nueva Ley de Seguridad Pública y del Estado aprobada en 2009 que sustituye a la tradicional y cuestionada Ley de Seguridad Nacional de 19789, anclada en doctrina e intereses estadounidenses. La nueva Ley basa su mirada en el concepto de seguridad integral y redefine un nuevo espacio estatal de articulación para la seguridad del Estado alrededor del Consejo de Seguridad Pública y del Estado (COSEPE). De igual forma, se 
incorpora a esta Ley una sección explícita sobre inteligencia, creando así la nueva Secretaría Nacional de Inteligencia (Rivera, 2011).

Sin embargo, y a pesar de existir todas estas modificaciones legales, no observamos mayores avances en la Policía Nacional respecto a su carácter doctrinario, orgánico y funcional en la nueva Constitución, y esto tomando en cuenta que se habla por primea vez del concepto de seguridad ciudadana y se establece la necesidad de coordinación con los gobiernos locales.

Las respuestas a esta ausencia de agenda reformista pueden venir de distinta índole; sin embargo, el caso ecuatoriano no parece alejarse de las explicaciones que se han dado en la región para explicar las restricciones y fracasos de los modelos de reforma policial. Por ejemplo, Saín (2009) describe a esta situación como un producto inercial venido del poco interés y reducida conciencia estratégica de la izquierda para meterse a fondo en asuntos organizativos, doctrinales, culturales y funcionales de la policía, producto de su mirada reducida sobre la violencia y el delito, asumidos como un problema de agenda de reforma social, como la explotación, la desigualdad, la marginalidad (Sain, 2009).

Por otro lado, hay autores que encuentran las razones en el costo político de la reforma por estar asociado a la incertidumbre política y a la contingencia (Arias, Rosadas \& Saín, 2012), y porque existe ausencia de modelos referenciales en la región, ${ }^{7}$ pero, sobre todo, por la dinámica impuesta por la lógica del gobierno contra el delito, que se caracteriza por la primacía de las medidas y estrategias de control, el aumento a la carga emocional de la política criminal, el populismo punitivo, entre otras cosas (Garland, 2006).

En todo caso, Ecuador es el típico ejemplo donde la agenda reformista no parece haber alcanzado o entendido la dinámica del pro-

\footnotetext{
7 Una de las críticas principales generadas en los procesos de reforma policial en la región es que estos adolecen de referentes institucionales a seguir, provocando cierta confusión en los actores políticos. Todo esto dentro de un contexto democrático.
} 
blema de la seguridad. Todo esto, sin duda, incidió en una ausencia inicial de una agenda programática de reforma policial, sin dejar de estar exenta de conflictos con amplias repercusiones políticas en este proceso gubernamental.

\section{La agenda inicial y primeros conflictos}

La agenda inicial del gobierno estuvo marcada por un proceso dinámico de gestión a base de una lógica prueba-error-prueba, que contribuyó a generar una enorme conflictividad en el manejo de la seguridad ciudadana y produjo desconfianza en la institución policial. A pocos días de posesionado Rafael Correa, este empezó a promover una vertiginosa recuperación y fortalecimiento del Estado donde la Policía Nacional no fue la excepción. Como producto de esto se constituyó la Comisión de Modernización de la Policía como muestra de una nueva voluntad política. ${ }^{8}$ En marzo de 2008 se presentó por parte del Gobierno el Plan Nacional de Seguridad Ciudadana, que contempló la entrega de 320 millones de dólares y que se ejecutaría 3 años ${ }^{9}$ y la creación de la Unidad de Ejecución del Plan de Seguridad Ciudadana adscrita al Ministerio de Gobierno para implementar proyectos previamente presentados por la Policía Nacional.

Esta situación generó las primeras fricciones entre policía y autoridad civil, dado que por el lado del gobierno se planteó la necesidad de crear una unidad técnica que ayudara a la Policía a ejecutar los proyectos que no había podido ejecutar hasta entonces. ${ }^{10}$ Sin embargo, la ausencia de una coordinación adecuada, no exenta de celos institucionales por parte de la Policía y la falta de experiencia en cuestio-

\footnotetext{
8 En agosto de 2007, la Comisión de Modernización de la Policía presentó al presidente Rafael Correa el plan de reestructuración que incluía, entre otros puntos, mejoras para la seguridad ciudadana y la rehabilitación social, condiciones laborales, incremento de salarios y calidad de vida a nivel individual y familiar.

9 Para el año 2009, y tras problemas financieros provocados por la crisis económica a nivel mundial que afectarían los proyectos de inversión del gobierno nacional, este rubro de 320 millones asignados a la Policía sufrió recortes importantes en sus montos.

10 Hasta diciembre de 2007, la Policía Nacional no pudo ejecutar proyectos de inversión a pesar de la asignación de 60 millones de dólares ordenados por el Presidente de la República.
} 
nes policiales por parte del personal civil de la Unidad, terminaron minando su capacidad y eficiencia en la ejecución de proyectos hasta su completa desaparición a principios de 2011.

Pese a ello, la inversión estuvo enfocada en el equipamiento logístico de la policía con un $89 \%$ del total. La inversión en proyectos no logísticos, como campañas de prevención y formación policial fueron marginales (Ministerio de Gobierno, Cultos, Municipalidades y Policías, 2008); pero no solo la inversión de recursos y el equipamiento logístico fue la prioridad porque desde el año 2007, la Policía Nacional, al igual que las Fuerzas Armadas, han mejorado ostensiblemente sus remuneraciones (esto lo miraremos más adelantes). Asimismo, se han hecho inversiones en vivienda fiscal, mejoramiento en la administración de pases policiales para evitar la alta rotación y el desarraigo territorial de las policías, gratuidad para los proceso de selección y admisión policial, entre muchas cosas más.

Esta dinámica incrementó el presupuesto asignado a la Policía Nacional en estos siete años. Mientras en 2006 el monto fue de 550 millones de dólares, en 2012 este rubro creció a más de 1.100 millones; es decir, aproximadamente un $100 \%$ de crecimiento, manteniendo un promedio de 40.000 miembros en estos siete años. Desde el 2008, se han invertido casi 600 millones de dólares en la policía (gráfico 2); a esto hay que sumar los casi 265 millones de dólares para construir la Central de Llamadas de Emergencia ECU-911 a cargo del Ministerio Coordinador de Seguridad.

Frente a esta inversión, los resultados para el control del delito no fueron los esperados en los primeros años de gobierno. La tasa de homicidios alcanzó los niveles más altos de la década entre 2008, 2009 y 2010 por encima de los 18 por cada 100.000 habitantes, según la Policía Nacional. El robo a personas, por su parte, creció de 11.427 denuncias por año a casi 16.000 en 2010; el robo de motos de 2292 a 4888, y el robo de automotores de 4785 a 5996; por su parte, delitos como el secuestro express o saca pintas tuvieron un aumento considerable, que generó mucha alarma y temor en la población (Ministerio del Interior, 2014). 
Gráfico 2. Presupuesto Policial de Ecuador 2008-2013*

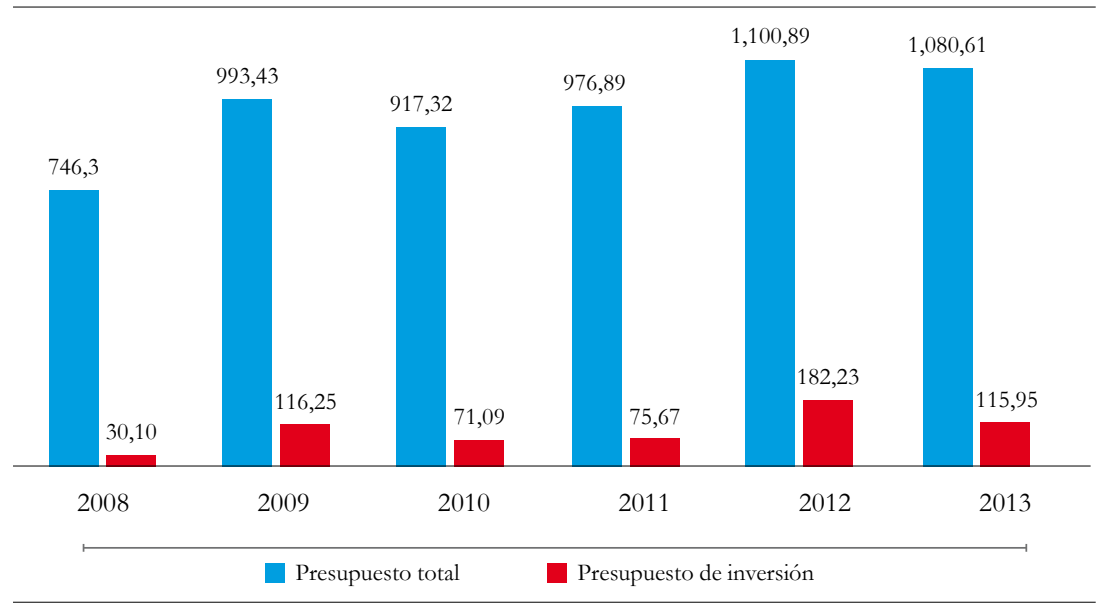

Fuente: Subsecretaría de Inversión Pública, SENPLADES, 2014.

*El dato de 2013 se refiere al presupuesto codificado. Se ha juntado la información de Policía con Ministerio del Interior para fines comparativos.

Por otro lado, de acuerdo con la Encuesta de Perfiles de Opinión realizada en febrero de 2012, se mostró que 72,8\% de los encuestados creía que el fenómeno de la delincuencia iba a empeorar en los próximos doce meses. Entre septiembre de 2009 y julio de 2011 el temor por la inseguridad subió de $32 \%$ a cerca de $47 \%$ en la población quiteña, lo cual es muestra de que el fenómeno tuvo crecimientos importantes.

Esta situación promovió que la seguridad ciudadana se convierta en espacio de disputa pública y un tema de altísima sensibilidad política que involucró a opositores y defensores del gobierno. ${ }^{11}$

La situación descrita puso a la Policía Nacional en el ojo del huracán con una altísima presión política para aumentar su efectividad, una fuerte exposición de opinión crítica sobre su credibilidad, un crecimiento de la demanda ciudadana por servicios policiales y el déficit de planificación institucional. De igual forma, frente a la premura por atender las demandas de seguridad ciudadana, se decretó en

\footnotetext{
11 Esto hasta el punto que la seguridad ciudadana se constituyó en el tema central de la Consulta Popular de mayo de 2011.
} 
reiteradas ocasiones estados de emergencia, con el objetivo de que las Fuerzas Armadas apoyaran a la Policía Nacional en el manejo y control de la seguridad interna. Actualmente, los militares operan directa y abiertamente de forma ocasional en labores de seguridad interna y ciudadana.

A nivel comparativo, en el gobierno de Correa se ha dado una mayor estabilidad, tanto a ministros como a comandantes de la Policía en comparación con el periodo 1979-2006; ${ }^{12}$ sin embargo, las tensiones gobierno/policía fueron constantes en los primeros años por varios temas, entre los que destaca la creación de la Comisión de la Verdad.

Esta comisión fue creada en 2008 para investigar casos de violación a los derechos humanos entre 1984 y 2008, y centró su mirada en el periodo gubernamental de León Febres Cordero (1984-1988), que fue acusado de aplicar una política de miedo, represión, persecución y desaparición de personas, cumpliendo con la doctrina de seguridad nacional. Según las conclusiones de esta Comisión, entre 1984 y 2008 la Comisión de la Verdad registró 118 casos, varios de ellos colectivos, con un total de 456 víctimas (Zambrano, 2010). ${ }^{13}$ Aunque no se han producido todavía sanciones entre los responsables, los resultados de esta Comisión generaron tensiones importantes en la relación gobierno/policía, pues de los 460 presuntos responsables, $49,6 \%$ corresponde a oficiales y miembros activos y pasivos de la Policía Nacional.

Otro elemento que marcó significativamente los conflictos en la relación gobierno/policía fue el bombardeo de las fuerzas militares colombianas en territorio ecuatoriano en febrero de 2008, que terminó con la muerte de Raúl Reyes, alto dirigente de las Fuerzas Armadas Revolucionarias de Colombia (FARC), y los efectos que produjo en

\footnotetext{
12 Hasta diciembre de 2013 existieron cinco ministros de Gobierno y cinco Comandantes de la Policía con un promedio de casi 16 meses de gestión. En el periodo 1979-2006, el promedio de permanencia en el cargo de un Ministro de Gobierno era de 7 meses.

13 Su mayor concentración se produjo en el gobierno de León Febres Cordero en el cual se agrupa el $68 \%$ de las víctimas, es decir, 311 personas.
} 
el país. Si bien ya se sabía por parte del gobierno del control e intromisión de agencias estadounidenses y colombianas en agencias de inteligencia ecuatorianas, la constatación fáctica de los peligros que acarreaba esta relación dio como resultado la ruptura inmediata de la cooperación entre Ecuador y Estados Unidos en contra de la lucha antinarcóticos y antiterrorista en el país y, posteriormente, generó una evaluación y reestructuración de los sistemas de inteligencia militar y policial en Ecuador. ${ }^{14}$

Este amargo incidente internacional del gobierno ecuatoriano y sus consecuencias políticas e institucionales, dio como resultado el descontento de una facción de funcionarios de inteligencia de la Policía Nacional que habían sido adoctrinados y subvencionados por el gobierno estadounidense. ${ }^{15}$

Esta relación de conflictos gobierno/policía tampoco estuvo exenta de rumores que fueron promovidos por ciertos grupos al interior de la policía y fuera de ella, para generar temores y fraccionamientos de la institución. Entre estos rumores destacan la desaparición del Instituto de Seguridad Social de la Policía (ISSPOL) para fusionarse con el Instituto Ecuatoriano de Seguridad Social, y cambios en las políticas de las pensiones jubilares de la Policía. En varias ocasiones, el Gobierno nacional tuvo que pronunciarse de manera oficial para desmentir estas noticias.

\section{30 de septiembre y sus consecuencias}

Sin lugar a duda, el acontecimiento de mayor relevancia en el conflicto gobierno/policía lo marcó el amotinamiento policial ocurrido el 30 de septiembre de 2010. En efecto, la acción pasó de una simple protesta policial y militar por la aprobación en la Asamblea de la nueva Ley de

\footnotetext{
14 En el año 2009 se aprobó la Ley de Seguridad Pública y del Estado que modificó y dio cabida legal al nuevo sistema de inteligencia del Ecuador.

15 En 2009 se dio paso a la firma de nuevos convenios de cooperación con Estados Unidos, pero esta vez con estrictos protocolos de supervisión y control del mando policial ecuatoriano.
} 
Servicio Público, y se transformó en un proceso de desestabilización política de las más importantes sufridas por este Gobierno.

El detonante principal de este acontecimiento fue la integración de las Fuerzas Armadas, la Policía Nacional y la Aviación Civil a la nueva Ley de Servicio Público en Ecuador, porque estas instituciones se habían mantenido al margen de las regulaciones legales del servicio público convencional mediante un régimen especial que les daba ciertos beneficios y privilegios. Otra razón fundamental fue la molestia policial y militar por la prohibición que establecía esta ley a recibir pagos extras y compensaciones adicionales por condecoraciones y ascensos como tradicionalmente se venía haciendo al interior de estas instituciones.

El 30 de septiembre de 2010, efectivos policiales y militares suspendieron sus jornadas laborales, bloquearon carreteras, impidieron el ingreso de asambleístas oficialistas a las instalaciones de la Asamblea Nacional y bloquearon el antiguo aeropuerto Internacional de Quito a través de algunos miembros de la Fuerza Aérea Ecuatoriana. Sin embargo, el mayor nivel de conflictividad se concentró en el Regimiento policial de Quito, cuando personal de tropa policial se alzó en protesta generalizada que derivó en agresiones, uso de gases lacrimógenos y la retención forzada del Presidente, según la mirada oficialista, ${ }^{16}$ una vez ingresado a las instalaciones del hospital policial contiguo al regimiento.

El resultado de este acontecimiento implicó también agresiones policiales a la población civil, grandes saqueos a locales comerciales en la ciudad de Guayaquil producto de la inacción policial y lo más grave de todo, las agresiones e intento de magnicidio que hubo contra el Presidente de la República. Por esta razón, por orden presidencial se dispuso la entrada de fuerzas especiales de la policía y militares para rescatar al Presidente que derivó en un cruce abierto de disparos y

\footnotetext{
16 Existe una gran polémica detrás de este suceso. Desde el lado oficialista, se maneja la figura de "secuestro." Desde algunos cuadros policiales se manejó la figura de una permanencia voluntaria del Presidente en el hospital de la policía.
} 
la muerte de 10 personas entre policías, militares y civiles, así como cientos de heridos.

Dos son las secuelas que este conflicto trajo a nivel institucional: 1) La sumisión de la Policía Nacional a la peor crisis de legitimidad ante la población desde el regreso a la democracia; y 2) una altísima desconfianza del mando gubernamental a la institución policial.

Las consecuencias de este suceso no se hicieron esperar. Casi inmediatamente se removió al Secretario Nacional de Inteligencia, se cambió a la alta cúpula policial y se inició una serie de investigaciones judiciales a cargo de la Fiscalía para determinar responsables y perpetradores de las agresiones contra el Presidente y demás acciones violentas. Las investigaciones y los concernientes juicios de responsabilidad duran hasta nuestros días.

Varias son las interpretaciones otorgadas a este suceso, las cuales se han impregnado de un alto nivel de politización. Pese a ello, lo que sí se puede afirmar es que este hecho fue el detonante para activar una serie de tensiones existentes desde 2007. Por esta razón, se veía también la necesidad de acelerar y profundizar cambios o reformas institucionales en la Policía Nacional y una nuevo tipo de relación policía-autoridad civil en el manejo de la seguridad interna del país.

\section{Reforma legal e institucional de la policía}

Luego del 30 de septiembre, el primer paso dado por el Presidente fue la emisión del decreto 632 del 17 de enero de 2011, que puso fin a la autonomía legal, administrativa y financiera que había tenido la Policía Nacional desde la Ley Orgánica de 1998. Con esta medida, se buscó poner fin al corporativismo y autogobierno policial en el manejo de la política pública institucional, que fue atribuida como uno de los factores estructurales del aislamiento, abandono y discrecionalidad policial. Con este decreto toda la gestión institucional quedó en manos del Ministerio del Interior, ahora responsable de la conducción y planificación estratégica de la institución policial. 
De manera paradójica, aunque esta reforma significó un cambio estructural profundo en la relación gobierno/policía en Ecuador, la institucional de la Policía sigue regida por la Ley Orgánica y de Personal de 1998. Por esta razón, el 30 de septiembre de 2011, un año después del levantamiento policial, se presentó a la Asamblea el proyecto de Nuevo Código Orgánico de Entidades de Seguridad. Este proyecto ha sido hasta ahora la expresión política más importante por establecer las bases de un nuevo modelo policial en Ecuador.

En materia de la Policía Nacional, este proyecto unifica en un solo cuerpo legal la parte orgánica de la policía, el manejo de personal y el régimen disciplinario. Actualmente, estos temas son manejados separadamente a través de dos leyes, Ley Orgánica y Ley de Personal, mientras que el tema disciplinario se maneja por medio de reglamento. Sin embargo, y pese a estos esfuerzos dogmáticos y orgánicos por superar el modelo militarista de la policía, la estructura sigue estando orientada por valores castrenses, ya que conserva la estructura centralizada, jerarquizada y disciplinaria donde los grados y la carrera policial siguen siendo parecidos a la institución militar. En consecuencia, desde la perspectiva neoinstitucional, de lo que empezó siendo una importante motivación y oportunidad histórica para establecer cambios profundos y urgentes en la institución policial, terminó siendo una réplica mejorada del régimen policial tradicional; es decir, un modelo colonizado e influido por los valores policiales tradicionales y sin la prioridad y urgencia política para impulsarlos. ${ }^{17}$

En consecuencia, lo que ha vivido Ecuador hasta el momento en materia de reforma policial es un nuevo proceso de organización de los servicios policiales en su conjunto y una reconfiguración del mando sujeto a la conducción gubernamental. En septiembre de 2012 se publicó la nueva Doctrina Policial de la República del Ecuador (Ministerio del Interior, 2012). Este nuevo documento incluye acápites importantes sobre la nueva identidad policial con una vocación civil y orientación comunitaria. No obstante, esta institución sigue

\footnotetext{
17 El Proyecto de Ley sigue hasta el día de hoy en manos de la Asamblea Nacional y no ha sido aprobado aún.
} 
estando orientada por los valores castrenses para una institución de más 42.000 miembros debido a su estructura piramidal y jerárquica.

\section{Desconcentración territorial}

Uno de los procesos más importantes dentro del proceso de organización de la Policía Nacional del Ecuador ha sido, sin duda, el proceso de desconcentración territorial basado en el modelo de zonas, circuitos y distritos. Este modelo, iniciado a mediados del 2010 y promovido por la Secretaría Nacional de Planificación y Desarrollo SENPLADES, en realidad no es más que un sistema de planificación territorial para superar el esquema de desconcentración nacional basado en el criterio político de provincias, cantones y parroquias; además, incluye parámetros más equitativos, como la densidad poblacional, la extensión territorial y la concentración de problemas (Secretaría Nacional de Planificación y Desarrollo, 2014).

Al ser la institución policial una de las entidades más desconcentradas del Estado, rápidamente el gobierno se dio cuenta de la importancia política que significaba establecer un adecuado sistema de acceso poblacional a los servicios policiales. A esta cuestión se sumaba la necesidad de tener un control y uso más eficiente de los ingentes recursos invertidos y por invertirse en infraestructura policial, como la construcción y reparación de unidades de policía comunitaria UPC, unidades de vigilancia comunitaria UVC, cuarteles policiales, vivienda fiscal, laboratorios de criminalística, escuelas de formación, entre otras cosas más. Por este motivo, la Policía Nacional fue una de las primeras instituciones en adherirse y participar de este nuevo esquema de planificación territorial del Estado.

Este modelo generó ciertos niveles de resistencia y rechazo al interior de la Policía. Por esta razón, se propuso desde el Ministerio del Interior la creación de un nivel intermedio de desconcentración por encima del nivel distrital, al que se denominó comando zubzonal, y que no es más que el mantenimiento de los viejos Comandos Provinciales, es decir, una estrategia institucional de la Policía para preservar viejas estructuras organizacionales en un proceso de cambio institucional. 
El modelo planificado de desconcentración policial también fue costeado por la Secretaría de Planificación, previendo una inversión de más 1.400 millones de dólares a 2017 y la incorporación adicional de 17.000 miembros policiales. Todo esto para cumplir normas internacionales sugeridas en relación con el número de policías necesario, que para 2017 llegaría a 57.000 miembros en Ecuador; es decir, más de 3.5 policía por cada 1.000 habitantes (gráfico 3).

Gráfico 3. Evolución de integrantes de la Policía Nacional de Ecuador 1990-2017

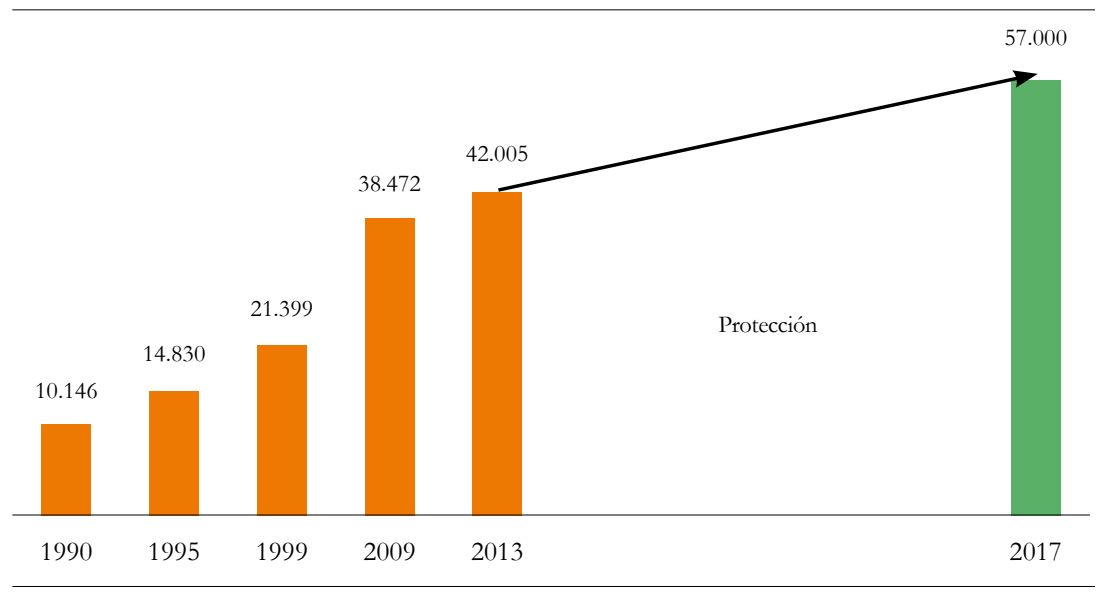

Fuente: elaboración propia con información de la Policía Nacional del Ecuador.

En general, este modelo planificado de acercamiento a la población ha generado una mejora en la imagen institucional. Por ejemplo, según la Encuesta de victimización y percepción de seguridad elaborada por el Municipio de Quito en 2013, reveló un mejoramiento de la percepción de la policía en la ciudad capital, porque en 2011, 63,6\% de los encuestados declaró que hay mayor presencia de policía en el barrio, mientras que en 2013 esta cifra subió a 81,3\%. Asimismo, $43 \%$ evaluó el trabajo de la policía en su barrio con excelente y bueno en 2013, mientras que en 2011 lo hizo solo un 35\%. El 56\% de los encuetados declaró que el realizar patrullajes en su barrio es la labor más precisada de la policía (CIMACYT, 2013).

Esta mejora en la credibilidad de la Policía producto de la estrategia planificada de acercamiento a la población, fue rápidamente valorada 
por sus potenciales políticos. Esto generó que la inauguración de Unidades de Policía Comunitaria en el territorio se constituyera en una estrategia central en la campaña política de reelección presidencial de 2013, que ayudó al Presidente de la República a ganar las elecciones con respaldo de más de $57 \%$ de la población (Consejo Nacional Electoral, 2014a).

\section{De la necesidad a la oportunidad: control delictual y revolución ciudadana}

La política de seguridad ciudadana y control delictual del gobierno ha tenido desde sus inicios una orientación hacia el trabajo reactivo y disuasivo policial, entre lo que se incluía también el involucramiento de las Fuerzas Armadas en materia de patrullajes, control de armas, control de narcotráfico, control de minería ilegal, invasiones, y en ciertas ocasiones al control del orden público. En 2011 se volvió a lanzar el nuevo Plan de Seguridad Integral donde la Agenda de Seguridad Ciudadana incluía cuatro ejes programáticos y 15 políticas. Esta vez, la orientación giraba principalmente en torno al trabajo policial para el control delictual y casi no decía nada respecto a la incorporación de gobiernos locales en la problemática.

Esto no quiere decir que no se hayan tomado otro tipo de medidas por parte del gobierno para fortalecer la política de seguridad ciudadana y de prevención de la violencia; por ejemplo, apoyados en la mirada de la prevención situacional del delito, en el año 2007 se prohibió la importación de armas de fuego y se estableció una lucha profunda a la fabricación informal de armas de fuego. Igualmente, se lanzó en el 2009 el Plan Para la Erradicación de la Violencia Intrafamiliar, de Género y contra las niñas, niños y adolescentes, y el Plan para la erradicación de cachinería (lugares de ventas de artículos robados). Pese a ello, el énfasis político siempre estuvo enmarcado en el fortalecimiento policial para responder a las demandas de seguridad ciudadana,

Ahora bien, como vimos anteriormente, la inseguridad ciudadana producto del crecimiento de ciertos delitos contra la propiedad y las 
personas fue el "talón de Aquiles" de la gestión del gobierno de la revolución ciudadana durante los primeros años de gestión. Según datos de la Policía Nacional, en 2008 la tasa de homicidios por cada 100.000 habitantes había llegado a los niveles más altos de los últimas dos décadas, ya que llegó a cifras de 19 homicidios por cada 100.000 habitantes. Esta se mantuvo a niveles superiores a los 18 por cada 100.000 habitantes entre los años 2009 y 2010. De igual forma, crecimientos importantes de delitos, como el secuestro express y otro tipos de delitos contra las personas con alto impacto mediático generaron una estela importante de inseguridad en la población y por ende la principal demanda ciudadana en la agenda pública.

Bajo la lógica del gobierno, el tema de seguridad ciudadana se constituyó en una política fallida, pues no se justificaba los altos niveles de inversión para la Policía Nacional y el sistema carcelario con tan pobres resultados en cuanto a la disminución de delitos. Esta situación fue rápidamente aprovechada por grupos políticos de oposición que, valiéndose de una agenda conservadora, acusaron a las políticas garantistas impulsadas por el gobierno en la Constitución de 2008 como el principal detonante de esta escalada delictiva (El Universo, 2009).

Como consecuencia de esto, en enero de 2010 el Presidente de la República impulsó una consulta popular para modificar o establecer reformas a la justicia destinadas a mejorar la seguridad ciudadana (Hoy, 2011). El triunfo del gobierno en la Consulta Popular fue ajustado. El promedio general de las 10 preguntas fue de un $47,12 \%$ a favor de la propuesta oficialista frente a un $41,8 \%$ en contra (Consejo Nacional Electoral, 2014b). Se decretó entonces la emergencia en el sector justicia por parte del Presidente de la República y se asignaron 600 millones de dólares para la transformación del sistema de Justicia en todas sus unidades; esto incluía el control disciplinario, la reducción de la corrupción y sanciones a la negligencia administrativa (Consejo Nacional de la Judicatura, 2014a).

De forma paralela a esta reforma judicial, en materia policial se dio un giro importante a partir de la Consulta popular al establecer acciones que tenían como objetivo dar golpes contundentes a la delincuencia 
bajo el lema de cero tolerancia a la delincuencia común y organizada. Uno de los programas más representativos impulsado desde el inicio por el Ministerio del Interior ha sido la campaña los más buscados, que contempla la participación de la ciudadanía con la entrega de información confidencial a cambio de recompensas económicas. Hasta diciembre de 2013, 182 delincuentes de alta peligrosidad fueron capturados y puestos a las órdenes judiciales, siendo 2012 el año de más alta proactividad policial en esta materia (Ministerio del Interior, 2014a).

Las críticas a este programa no se han hecho esperar. En primer lugar, no se sabe a ciencia cierta si realmente existe una mayor proactividad policial al respecto, puesto que nunca se ha entregado información que permita constatar esta actividad con lo hecho anteriormente por la policía. A este programa de los más buscados se unió la creación de la línea telefónica 1800 delitos (Ministerio del Interior, 2014).

Esta alta proactividad política contra el delito ha estado también respaldada con una alta productividad policial; por ejemplo, según la Red Latinoamericana de análisis de Seguridad y Delincuencia Organizada (RELASEDOR, 2014), el número global de detenidos efectuado por la Policía Nacional subió de 24.449 personas en 2011, a 33.437 en 2013. Igual situación ocurre con las bandas delincuenciales desarticuladas, porque según datos del Ministerio del Interior, en el año 2010 se desarticularon 699 bandas y en 2013, 768 (Ministerio del Interior, 2014b). En materia de narcotráfico, la productividad mejoró pasando de 18 toneladas de droga incautada en 2010, a más de 57 toneladas en 2013 (RELASEDOR, 2014).

Por lo tanto, esta situación es una muestra clara del tipo de política gubernamental en materia de seguridad luego de la consulta de mayo de 2011. En primer lugar, una recomposición del mando gubernamental hacia la Policía Nacional, donde el Ministerio del Interior ha sido su más fiel intérprete y gestor, generando así una sinergia institucional importante gobierno/policía para la lucha contra ciertos delitos. En segundo lugar, pragmatismo en la gestión de la seguridad, que consiste en ejecutar lo que se tenía programado anteriormente bajo un mejor esquema de planificación. En efecto, al evaluar los informes 
de gestión del Ministerio del Interior, no se mira mayores avances respecto a la generación de nuevas líneas estratégicas de política. Por último, se observa una amplia gestión política de la seguridad que ha buscado legitimidad social basada en una mirada punitiva y conservadora contra la delincuencia y la implementación de estrategias de disuasión policial y prevención situacional, que han ampliado los mecanismos de control ambiental del delito.

Uno de los programas símbolo de este sistema es el Sistema Integrado de Seguridad ECU 911. En febrero de 2012, el Ministerio Coordinador de Seguridad puso en marcha este sistema con una millonaria inversión de más de 230 millones de dólares; este consiste en integrar en un solo sistema la central de llamadas de emergencias nacionales y el sistema de video vigilancia con alto nivel de infraestructura tecnológica. En los momentos actuales se cubre 78\% de la población ecuatoriana y la satisfacción ciudadana llega a 82\% (Ministerio Coordinador de Seguridad, 2014, pp. 154-157).

Estas acciones emprendidas por el gobierno a partir de mayo de 2011 han venido aparejadas con mejoras en los índices de ciertos delitos. Por ejemplo, se ha promocionado con insistencia las reducciones importantes en materia de homicidios, la misma que presentó una reducción de casi 7 puntos entre 2010 a 2013 pasando de 17,57 por cada 100.000 habitantes a cerca 10,92, respectivamente (Ministerio del Interior, 2014a). A esta reducción, expuesta como la carta de presentación de los logros en materia de seguridad del gobierno durante los últimos años, también se suman las disminuciones en los homicidios por armas de fuego y la disminución del secuestro express, que pasó de 896 casos en 2010, a 494 en 2013, entre otros delitos (gráfico 4).

Aunque de parte del gobierno se ha atribuido esta reducción a una diversidad de acciones implementadas para el control delictual en el país desde 2007, como la prohibición del porte de armas, la regulación al consumo de alcohol y la mejoras en los rendimientos de la justicia penal producto de la intervención en este sector a partir del 2011, no se puede aún establecer de manera técnica las causas objetivas de esta disminución en ciertos índices delictivos. 
Gráfico 4. Tasa homicidios 2007-2013

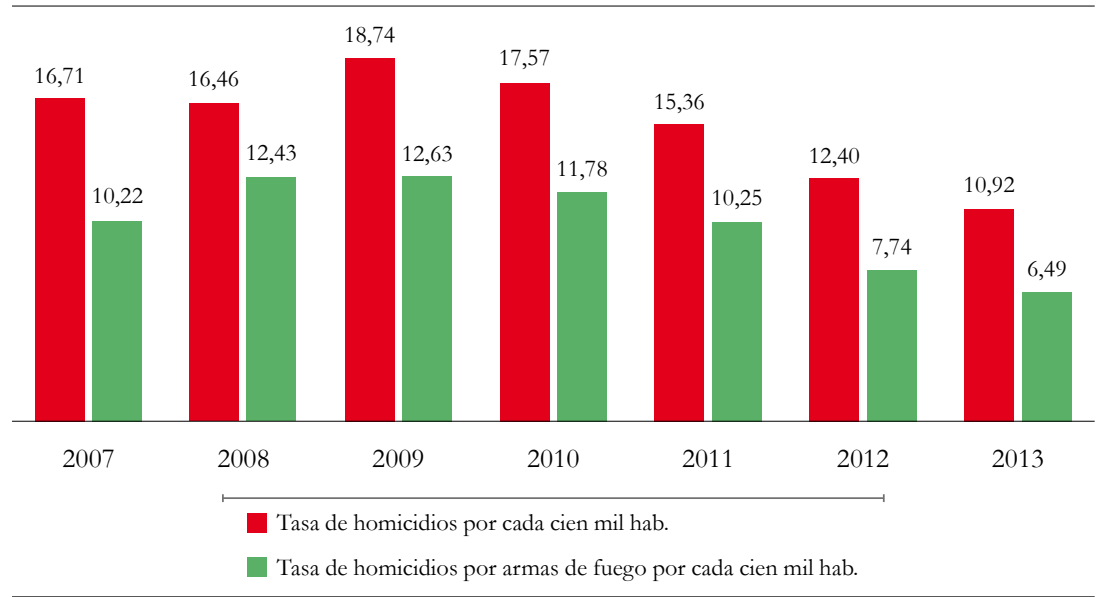

Fuente: elaboración propia con información del Ministerio del Interior (2014a) y Secretaría Nacional de Planificación y Desarrollo (2013).

En diciembre de 2013 fue aprobado por unanimidad y tras un largo proceso de debate el nuevo Código Orgánico Integral Penal que vino a reemplazar al viejo Código Penal ecuatoriano implementado en los años sesenta. En este Código, se tipifican nuevos delitos, se suprimen ciertos delitos en desuso y se aumentan las penas en varios delitos. ${ }^{18}$

Es crucial indicar que la política actual respecto al control del delito, generada por el gobierno de Rafael Correa en los últimos años, debe ser interpretada como producto de una nueva forma de entender y gestionar el problema del delito en las sociedades contemporáneas, es decir, partiendo del miedo a la delincuencia y por ende el surgimiento de la justicia expresiva, basados en los sentimientos de la víctima antes que en la rehabilitación del delincuente; así, los discursos populistas surgen como forma de legitimación social, donde el crecimiento de la seguridad privada, como forma de gobierno a distancia, entre otras cosas, fundamenta un nuevo tipo de control que no se limita solo a lo delictual, sino a la sociedad en su conjunto (Garland, 2006).

18 Este Código entró en vigencia en agosto de 2014. Forman parte de este nuevo cuerpo legal 730 artículos e incluye 77 nuevas infracciones. Se establece la acumulación de penas de hasta 40 años y se tipifican delitos como el sicariato, feminicidio. 
No obstante, resulta paradójico que no exista distancia ideológica de este modelo con las caracterizadas por sociedades tardomodernas, que se caracterizan por el triunfo de la economía de mercado y la ideología neoliberal. Por otro lado, lo dicho puede ser también interpretado como parte de un proceso de cultura política latinoamericana que busca en el control y el autoritarismo Estatal una salida para el desarrollo y la modernización social. En este sentido, el miedo a la delincuencia termina siendo una nueva fuente legitimadora de este proceso.

\section{Investigación criminal}

Las tareas de la investigación criminal en el Ecuador están a cargo de la Policía Judicial que es un cuerpo auxiliar dirigido por la Fiscalía y acreditado para la investigación judicial, pero en su totalidad integrado por personal especializado de la Policía Nacional. Por esta razón, los miembros de la Policía Judicial dependen jerárquica, disciplinaria, administrativa y operativamente de la Policía Nacional. Las funciones de la Policía Judicial comprenden también todas las diligencias investigativas que realicen los diferentes servicios de la Policía Nacional bajo la dirección y el control de la Fiscalía, como el de antinarcóticos, investigación de accidentes de tránsito, de secuestros y extorsión, y otros que por necesidad de prevenir y combatir el delito existen o se crearen.

Dentro de la Policía Nacional, una de las instancias más deprimidas y abandonas ha sido sin duda la Judicial. Esta situación ha sido atribuida a la falta de inversión en esta dependencia, debido a problemas de desinterés gubernamental o irresponsabilidad de los mandos policiales en la planificación institucional. Se llegó a la situación donde el presupuesto de la Dirección Nacional de la Policía Judicial e Investigaciones se financiaba con recursos de autogestión, provenientes de la venta de especies valoradas y remate de bienes recuperados. En 2009 este presupuesto ascendió apenas a 10 millones de dólares, donde más de la mitad se utilizaba en gasto corriente y apenas un $10,2 \%$ de este monto se destinaba a inversiones. 
Esta situación subsumió a la Policía Judicial en una profunda crisis institucional, convirtiéndola en una unidad con enormes problemas de corrupción, descrédito ciudadano y acusada de violaciones a los Derechos Humanos. En efecto, en 2009 desapareció por orden gubernamental el Grupo de Apoyo Operacional (GAO) dependiente de la Policía Judicial por graves denuncias de tortura y ejecuciones extrajudiciales, entre las que se cuentan más de 84 durante 2000 y 2008 (Comisión Ecuménica de Derechos Humanos, 2009).

En 2011 se presentó el informe sobre las ejecuciones extrajudiciales, sumarias o arbitrarias, elaborado por Philip Alston, Relator Especial de la Naciones Unidas. En este informe se establecen una serie de observaciones sobre el proceso de investigación criminal donde se encontraron graves deficiencias y negligencia institucional en el manejo de este importante sector de la investigación judicial (Alston, 2011).

Las respuestas del gobierno a esta crisis institucional han venido de la mano de una serie de inversiones destinadas a modernizar la capacidad técnica y operativa de la Policía Judicial, y a mejorar sus servicios a la ciudadanía. En la actualidad, la Policía Judicial ya es parte de la planificación presupuestaria anual de la Policía Nacional, sin embargo, no se ha visualizado una reorganización de los servicios de Policía Judicial porque sigue siendo la misma del año 2009 (gráfico 5).

Desde el año 2008, se planificó la creación de nuevos laboratorios de criminalística en Quito y Guayaquil. En 2012 se inauguró el nuevo laboratorio de criminalística en la ciudad de Quito para el apoyo al trabajo de la Policía Judicial; en este se incorporó tecnología de punta una infraestructura moderna y formación del talento humano (Ministerio del Interior, 2014a). En 2009, el numérico de Policía Judicial en el país era de 3.319, y en 2013 subió a 4.078 agentes. En los últimos años, el Ministerio del Interior atribuyó que la reducción de los homicidios en el Ecuador, así como otros delitos se deben a mejoras sustanciales en los procesos de investigación criminal; sin embargo, no se dispone de una línea de base de años anteriores que permitan corroborar esas mejoras. 


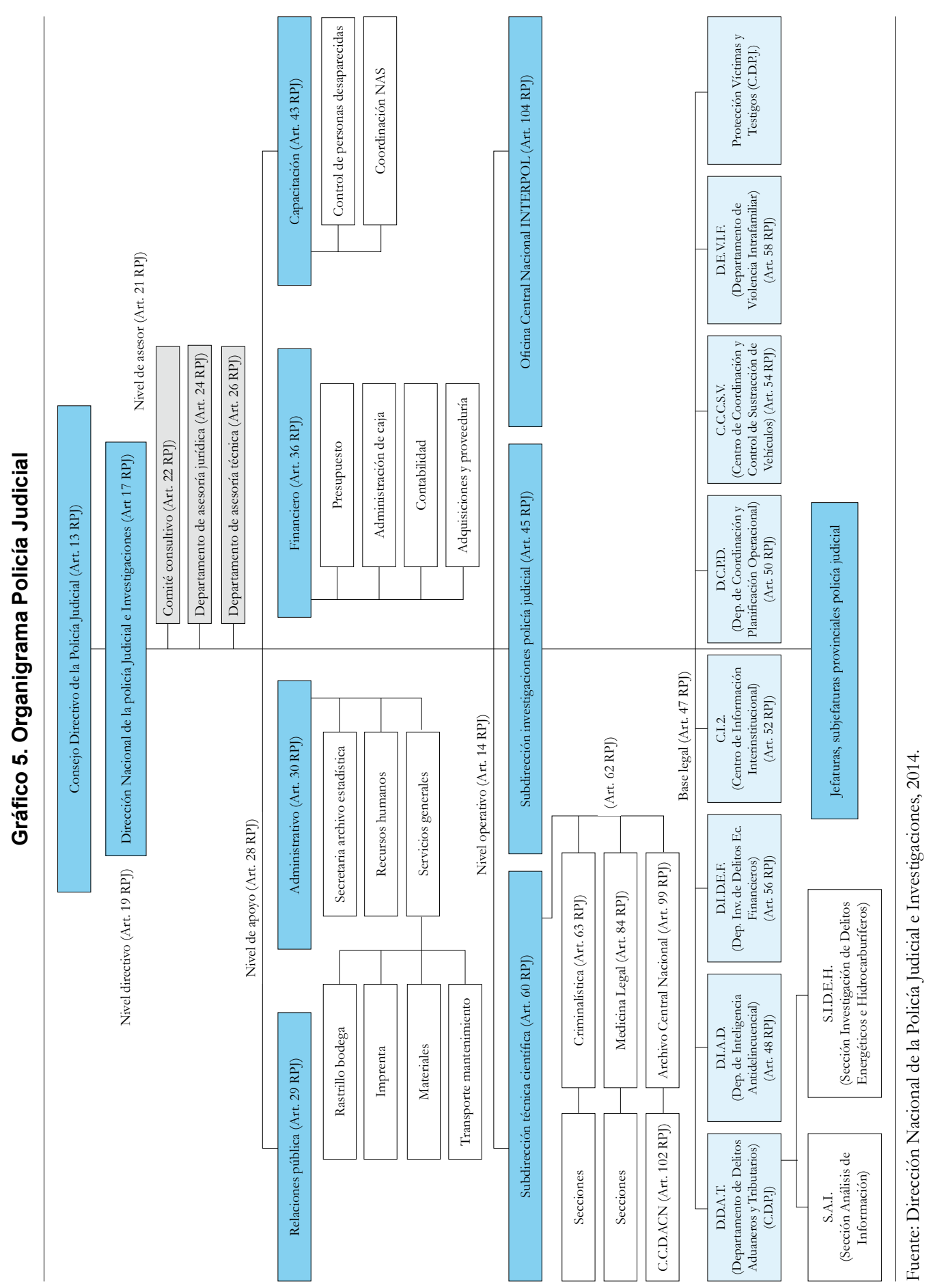


La problemática se complica por cuanto existe descoordinación entre la Fiscalía y la Policía Nacional. ${ }^{19}$ El desafío más importante de este cuerpo especializado es poner en marcha su implementación en un contexto de fuertes restricciones presupuestarias, ya evidenciadas en el año 2014 por parte del gobierno nacional.

\section{Bienestar policial}

El personal policial ha sido una preocupación central del Gobierno nacional desde 2007. La Constitución de 2008 establece los lineamientos fundamentales donde se estipulan los derechos y obligaciones del personal policial y militar bajo los criterios de bienestar, igualdad de oportunidades y profesionalización; además, indica que los miembros de las Fuerzas Armadas y de la Policía Nacional estarán sujetos a las leyes específicas que regulen sus derechos y obligaciones, y su sistema de ascensos y promociones con base en méritos y con criterios de equidad de género. También se garantizará su estabilidad y profesionalización.

El Plan de Seguridad Ciudadana lanzado en el 2008 tuvo, entre sus fines, dotar de los instrumentos básicos para el correcto funcionamiento a la Policía y optimizar sus instalaciones para mejorar las condiciones de vida. Dentro de los proyectos impulsados en ese Plan estuvo el programa de vivienda fiscal, que consistía en la construcción de casas para miembros en servicio activo de la Policía Nacional. Los programas se han venido entregando a lo largo de todo el país desde el año 2010, y se prevé entregar 6.000 viviendas planificadas hasta el 2015. Vale destacar que hasta enero de 2013 se entregaron 3.600 viviendas para cubrir el déficit habitacional (El Telégrafo, 2013a).

\footnotetext{
19 En reiteradas ocasiones, la Fiscalía General del Estado ha reclamado la competencia de asumir el control administrativo de la Investigación Criminal, basada en la norma constitucional número 195 que dice que esta entidad "organizará y dirigirá un sistema especializado integral de investigación, de medicina legal y ciencias forenses, que incluirá un personal de investigación civil y policial" (Constitución de la República de Ecuador, 2008). No obstante, como hemos visto, esta labor a está a cargo de la Policía Nacional, lo cual ha generado problemas en la coordinación interinstitucional y por ende en la calidad de la investigación judicial.
} 
Una de las señales más significativas del Gobierno respecto a la dignificación del trabajo policial fue sin duda el incremento salarial. Desde 2007 existió un progresivo aumento en el ingreso policial. En los momentos actuales, un policía recién ingresado a la institución recibe de ingreso 933 dólares, cantidad casi tres veces mayor que lo recibido en 2007. Como se puede ver en el gráfico 6, este ingreso duplica el costo de la canasta básica familiar para un cabo segundo de policía. Esto ha sido, incluso criticado para varios sectores sociales, dado que el ingreso básico de la Policía supera en creces el ingreso de un médico recién egresado y el de un maestro, habiendo cursado menos años de estudio.

Gráfico 6. Salarios de la Policía Nacional 2000-2014

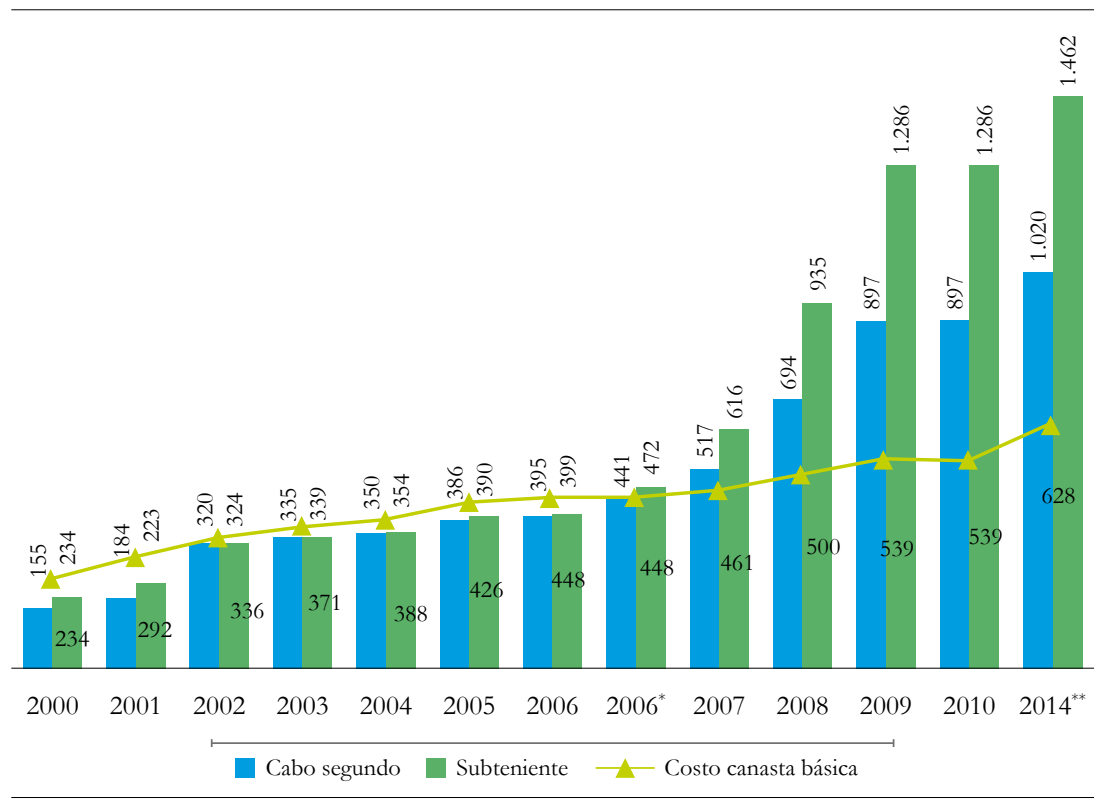

Fuente: Secretaría Nacional de Planificación y Desarrollo.

*Año de la homologación salarial con las Fuerzas Armadas

** Información a enero 2014

Otra de las mejoras realizadas respecto al bienestar policial fue la reforma para acabar con la extenuante carga laboral de la Policía, al establecer medidas correctivas para que los horarios de trabajo se rebajen a 8 horas en lugar de 12. Asimismo, con la nueva Ley de Servicio Público aprobada en 2010 y que fue el detonante del 30 
de septiembre, se reconoce el pago de horas extras cuando se supera las 40 horas de trabajo semanal, aunque se suprimía el reconocimiento de beneficios económicos producto de condecoraciones y ascensos.

Adicional a estas medidas, esta ley busca evitar en cierta forma la alta rotación del personal en los territorios. Tradicionalmente, esta rotación ha afectado al bienestar policial en la estabilidad familiar y ha creado el fenómeno del desarraigo que complica los valores de la policía comunitaria en su cometido de sentido de pertenencia y conocimiento territorial.

Ahora bien, pese a este importante esfuerzo gubernamental por mejorar las condiciones laborales y de bienestar policial que es uno de los logros del gobierno de Rafael Correa en materia policial, persisten aún problemas internos en la institución que atentan directamente contra el bienestar de personas. Son reiteradas las denuncias sobre problemas de alcoholismo y drogadicción sin existir una estrategia institucional de salud ocupacional. De igual forma, y relacionada a esto último, persisten problemas de altas tasas de divorcio y desarraigo territorial. También se presentan denuncias de corrupción en el sistema de admisiones de la carrera policial, el manejo de pases, abusos y malos tratos al personal policial en el proceso de formación y control disciplinario como consecuencia de la persistencia de la doctrina castrense.

\section{Controles internos y justicia policial}

El sistema de controles internos y externos es una característica de las más importantes de las reformas policiales en contextos democráticos. A nivel institucional, uno de los avances más importantes que ha tenido Ecuador en materia de control civil de la Policía fue la disposición constitucional de plantear la unidad jurisdiccional de la justicia policial. Con la nueva Constitución se logró que la justicia policial pase a manos de la justicia ordinaria, a través de unidades especializadas en la materia. El control civil de la justicia policial es considerado un significativo logro en materia de reforma policial en América Latina, aunque en Ecuador estas salas especializadas siguen 
manejadas por ex policías. Se confirma entonces el peso de la inercia corporativa en estas instancias.

Ahora bien, no se han visto reformas importantes respecto a la estructura orgánica y funcional de los controles internos de la policía. La Inspectoría de la Policía Nacional sigue siendo una entidad dependiente del mando central, sin la autonomía institucional necesaria para realizar un adecuado trabajo de control de asuntos claves para la lucha contra la corrupción y los abusos policiales. En el nuevo proyecto de Ley del Código Orgánico de Entidades de Seguridad, tampoco se vislumbran cambios en esta materia.

Por el contrario, y fiel a cómo se ha venido manejando otras áreas policiales, en 2013 el gobierno nacional anunció un plan agresivo de modernización de la Inspectoría policial que contempla, entre otras cosas, una importante dotación de recursos para la construcción de nuevas instalaciones, incorporación de personal y la adopción de un Plan de Control y Confianza basada en un enfoque que interrelaciona estudios psicológicos, toxicológicos, socioeconómicos y poligráficos (El Telégrafo, 2013b). El objetivo de este Plan es evaluar a todo el personal de la Policía Nacional hasta 2017. Producto de las primeras evaluaciones internas 530 elementos fueron separados de la institución por faltas disciplinarias graves, reincidencia en mala conducta y delitos penales (Hoy, 2014).

Los pedidos de información de la ciudadanía sobre el funcionamiento policial los maneja el Ministerio del Interior desde 2011. Pese a que existe una buena legislación de acceso a la información pública en Ecuador, el acceso a la información en materia de seguridad y policía es bastante limitado a la ciudadanía en general, producto principalmente de la discrecionalidad ministerial para su otorgamiento, la inercia de lógicas seguritarias venidas de la Doctrina de Seguridad Nacional y la inexistencia de mecanismos y protocolos de acceso libre a la información estadística de seguridad, como sí ocurre con otros sectores a través del Instituto Nacional de Estadísticas y Censos (INEC). Esto dificulta el trabajo de control y monitoreo sistemático de corrupción y violaciones a derechos humanos por parte del personal policial en 
este periodo de gobierno. Consecuentemente, se podría decir que los avances pregonados en el tema de controles internos y externos a la gestión policial es un proceso a medias, caracterizado por una mirada unidireccional del sistema, condicionado y controlado en gran medida por la gestión gubernamental.

\section{Conclusiones}

El proceso de reforma policial en los siete años de gobierno de Rafael Correa no parece distanciarse demasiado del manejo de otras policías de la región durante el periodo de gestión de varios gobiernos progresistas. En primer lugar, esta situación se ha caracterizado por la ausencia de agendas programáticas en materia de reforma policial, producto del escaso interés de la izquierda política por los temas de seguridad, considerados a priori como coyunturales y condicionados por cambios estructurales de la sociedad. El acercamiento crítico a la realidad policial ha estado sujeto a una mirada dogmática y centralizada en los temas de abusos y violación a los derechos humanos. Por esta razón, el manejo policial durante el gobierno de Correa ha constituido un ejercicio de aprendizaje continuo, marcado por el pragmatismo en el ejercicio del poder y con un desempeño discontinuo, poco integral para lograr reformas sistémicas, y colonizado por una mirada y lenguaje policial que influye en el diseño de los planes de modernización y trasformación institucional. Una suerte de mimetización policial del gobierno civil.

En el caso de Ecuador, las conquistas más importantes, con las oscilaciones respectivas en materia de reforma y modernización policial, se encuentran influenciadas por el pragmatismo gubernamental y su concepción de Estado y política social, a saber: conducción política de la policía, desconcentración, política de bienestar policial, educación policial, y ciertos avances contra la corrupción y los abusos policiales. Por el contrario, existen limitaciones devenidas de las características de este tipo de gobiernos concentradores de poder y con alta susceptibilidad a la crítica pública. No pueden negarse las necesidades propias del gobierno contra el delito, donde ha primado la supremacía de la mirada policial sobre la inseguridad, el crecimiento de la industria 
de la seguridad privada, la concurrencia de la justicia expresiva y el manejo estridente de la fuerza pública para luchar contra el crimen que tiende a la militarización del problema.

Queda clara la existencia de dos periodos diferenciados en estos siete años respecto al tema policial y su relación con el gobierno. Desde el punto de vista neoinstitucional, estos momentos marcaron contextos diferenciados para las motivaciones y significados del gobierno sobre la cuestión policial. El primero de ellos, marcado por una dinámica de prueba y error en la conducción policial, generó un alto nivel de conflictividad y desconfianza institucional mutua, producto del conservadurismo de las policías en escenarios de cambio institucional profundo y el poco conocimiento del gobierno de temas policiales y de seguridad.

El segundo momento está relacionado con el desenlace y acontecimientos post 30 de septiembre de 2010 , porque marca la necesidad de tener un mejor manejo de la política de seguridad interna y la institucionalidad policial en el país. Se miran esfuerzos para retomar la conducción política directa de la policía, lograr una mejor sinergia gubernamental con el mando policial, reducir ciertos tipos de delito con alto impacto entre la población y recuperar la imagen policial ante la ciudadanía, todo esto ayudado por el triunfo político de la Consulta Popular del 11 de mayo de 2011, donde los temas de seguridad y justicia fueron los pilares fundamentales de ese proceso. Sin embargo, en estos momentos, existiría una colonización de la mirada policial sobre los problemas de seguridad que ha incidido en la composición orgánica y el manejo del personal. Algunos cambios más inmediatos e importantes están en veremos luego del 30S, debido a la permanencia de lógicas corporativas y un estancamiento del cambio doctrinario que no logra zafarse del síndrome militar.

Pese a ello, es necesario mirar el tema policial en Ecuador desde una mirada más general a lo que significa el ejercicio de gobierno. Esto quiere decir, la necesidad de pensar este proceso dentro de la lógica gubernamental progresista, modernizadora y la expansión de control social. En este escenario, no parece haber diferencias signi- 
ficativas con las experiencias vividas en otros países desde los años setenta, donde los cambios en la estructura social y económica de las sociedades, asociadas al triunfo de la ideología del libre mercado, dio paso al crecimiento del aparataje de control estatal basado en el miedo. Por ello, los cambios estructurales han sido determinantes para entender la agenda de reforma policial en seguridad, donde, si bien se ha ganado terreno en la conquista de ciertos derechos sociales y económicos en estos 7 años, también se han logrado avances en materia de control social.

El crecimiento del gasto en policía debe ser visto como parte de este proceso, pero también debe entenderse que el tema del control no se agota solo en la Policía Nacional. Prueba de ello es el incremento substancial del numérico policial, el crecimiento de la industria privada de seguridad y, por sobre todo, el crecimiento de la capacidad punitiva del Estado como mecanismo de control y regulación en otras áreas de la vida social y la gestión gubernamental. En otras palabras, un cambio sustancial en el ejercicio de gobierno porque existe una fuerte tendencia a la militarización de la seguridad interna que va de la mano con la aprobación del nuevo Código Orgánico Integral Penal. Una dinámica política un tanto perversa de avances y retrocesos, de juegos prueba-error-prueba que bien podría ser definida con la frase un paso adelante y dos pasos para atrás.

\section{Referencias}

Almond, G., Flanagan, S.C. \& Mundt, R.J. (1993). Crisis, elección y cambio. Zona Abierta, (63/64), 45-71.

Alston, P. (2011). Informe del Relator Especial sobre las ejecuciones extrajudiciales, sumarias o arbitrarias. Misión Ecuador. Quito: Consejo de Derechos Humanos, Asamblea General de las Naciones Unidas.

Arias, P., Rosadas-Granados, H. \& Saín, M. F. (2012). Reformas policiales en América Latina. Principios y lineamiento progresistas. Bogotá: F.E.S. Recuperado de http:/ /library.fes.de/pdf-files/bueros/la-seguridad/09383. pdf.

Arcos, C., Carrión, F. \& Palomeque, E. (2003). Ecuador, Seguridad Ciudadana y Violencia. Quito: FLACSO Sede Ecuador. 
CYMACYT (2013). Análisis estadístico descriptivo de la encuesta de victimización y percepción de seguridad del Distrito Metropolitano de Quito. Quito, D.M, Documento no publicado.

Comisión de la Verdad (sf). Violaciones de los Derechos Humanos en Ecuador 1984-2008. Recuperado de http:/ / www.dhnet.org.br/verdade/mundo/equador/cv_equador_3_059_244.pdf

Comisión Ecuménica de Derechos Humanos. (2009). Informe sobre el derecho a la integridad personal en el Ecuador 2009. Quito: CEDHU. Recuperado de http://www.cedhu.org/index.php?searchword=informe+ gao\&or dering $=$ \&searchphrase $=$ all\&Itemid $=37$ \&option $=$ com_search

Consejo Nacional Electoral (2014a). Resultados electorales de la elección presidencial en Ecuador 2013. Recuperado de http:/ / resultados2013.cne.gob.ec/ Results.html?RaceID $=1 \&$ UnitID $=1 \&$ IsPS $=0 \& L a n g I D=0$

Consejo Nacional Electoral. (2014b). Resultados de la Consulta Popular 2011. Recuperado de https://app2.cne.gob.ec/resultados/

Consejo Nacional de la Judicatura. (2014a). Acceso a la justicia: servicio y ciudadanía. Rendición de cuentas enero 2013-enero 2014.” Resumen. Quito: Consejo Nacional de la Judicatura. Recuperado de http://www. funcionjudicial.gob.ec/index.php/saladeprensa/multimedia/index. php?option $=$ com_flippingbook \&view $=$ book\&id $=11$ :rendicion 2014\&catid $=1$ :default-category\&tmpl=component

Consejo Nacional de la Judicatura. (2014b). Acceso a la justicia: servicio y ciudadanía. Rendición de cuentas enero 2013-enero 2014. Informe completo. Quito: Consejo Nacional de la Judicatura.

Constitución de la República del Ecuador. (2008). Quito: Asamblea Nacional del Ecuador.

Corporación Latinobarómetro (2004). Un informe-resumen latinobarómetro 2004 una década de mediciones. Recuperado de http:/ / www.latinobarometro.org Corporación Latinobarómetro (2011). Seguridad Ciudadana el problema principal de América Latina. Recuperado de http:/ /wwwlatinobarometro.org

Correa, R. (2005). Otra economía es posible En A. Acosta., y F. Falconí (Ed.), Asedios a lo imposible. Propuestas económicas en construcción. Quito: FLACSO Sede Ecuador y FES ILDIS. Recuperado de http: / /www.flacsoandes. edu.ec/biblio/shared/biblio_view.php?bibid=18052\&tab=opac

Dirección Nacional de Policía Judicial. (2014). Organigrama. Recuperado de http://www.dnpj.gob.ec/inicio/index.php/nosotros/2012-06-25-13-53-06/organigrama.html 
Fruhling, H. (2002). Luces y sombras en la reforma policial en América Latina. Revista de Análisis Político, 2(3), 23-44. Recuperado de http:// www.kas.de/wf/doc/1973-1442-4-30.pdf

Garland, D. (2006). La cultura del control. Crimen y orden social en la sociedad contemporánea. Gedisa: Barcelona.

March, J.G.x \& Oslen, J. P. (1993). El nuevo institucionalismo: factores organizativos de la vida política. Zona Abierta, (63/64), 1-43.

Ministerio Coordinador de Seguridad (2014). Plan Nacional de Seguridad Integral. Quito: Ministerio Coordinador de Seguridad.

Ministerio de Gobierno, Cultos, Municipalidades y Policía. (2008). Plan de seguridad ciudadana. Una nueva policía cerca de ti. Quito: Ministerio de Gobierno.

Ministerio del Interior. (2012). Doctrina Policial de la República del Ecuador. Quito: Ministerio del Interior. Recuperado de http://www.ministeriointerior.gob.ec/wp-content/uploads/downloads/2012/10/ Doctrina-Policial-de-la-Rep\%C3\%BAblica-del-Ecuador.pdf

Ministerio del Interior. (2014a). Agenda Sectorial de Seguridad Ciudadana". Seguridad Integral: plan y agendas 2014-2017. Quito: Ministerio Coordinador de Seguridad.

Ministerio del Interior. (2014b). Agenda Sectorial de Seguridad Ciudadana. En Seguridad Integral: plan y agendas 2014-2017, 1-98. Quito: Ministerio Coordinador de Seguridad.

Muñoz, P. (2012). ¿Cómo caminamos al Socialismo del Buen Vivir? Cinco años de Revolución Ciudadana desde el Plan Nacional del Buen Vivir. En Corriente Alterna, Ecuador: dilemas en las izquierda, (pp.19-25). Quito. Recuperado de http://www.flacsoandes.org/dspace/bitstream/10469/3731/1/REXTN-CA1-05-Mu\%C3\%B1oz.pdf

Policía Nacional del Ecuador (2007). Estadísticas delictuales. Documento no publicado.

Policía Nacional del Ecuador (2015). Sistema informático de la Dirección Nacional de Personal. Documento no publicado.

Pontón, D. (2007). Reforma policial en Ecuador: un tema relegado al olvido. Revista Urvio (2), 37-56. Recuperado de http://revistas.flacsoandes. edu.ec/urvio/article/view/37-56

Pontón, D. (2009). Policía comunitaria y cambio institucional en el Ecuador. Ecuador: FLACSO Sede Ecuador. 
Ramírez Gallegos, F. \& Minteguiaga, A. (2007). El nuevo tiempo del Estado. La política posneoliberal del correísmo. OSAL, (22), Año VIII. Recuperado de http://bibliotecavirtual.clacso.org.ar/ar/libros/osal/ osal22/D22RamirezGMinteguiaga.pdf

RELASEDOR (2014). Indicadores sobre gestión institucional. Recuperado de http://www.flacsoandes.edu.ec/relasedor/index.php/ecuador/ gestion-institucional

Rivera Vélez, F. (2011). La Inteligencia ecuatoriana: tradiciones, cambios y perspectivas. En F. Rivera V (Coord.), Inteligencia estratégica y prospectiva (s.p.), Quito: Flacso, Senain y Aecid.

Saín, M. F. (2009). La reforma policial en América Latina. Una mirada crítica desde el progresismo. Recuperado de http://www.flacsoandes.org/web/ imagesFTP/1246308259.la_reforma_policial_en_america_latina.pdf

Secretaría Nacional de Planificación y Desarrollo. (2013). Plan Nacional del Buen Vivir. Quito: Secretaría Nacional de Planificación y Desarrollo.

Secretaría Nacional de Planificación. (2014). ¿Cómo funcionarán estos niveles administrativos de planificación? Recuperado de http://www.planificacion.gob.ec/5-como-funcionaran-estos-niveles-administrativos-deplanificacion/

Sozzo, M. (2005). Policía violencia y democracia. Nota genealógica. En M. Sozzo (Dir.). Policía, violencia y democracia. Ensayos sociológicos, 161-208. Buenos Aires: Universidad Nacional del Litoral.

Zambrano, A. (2010). Conclusiones de la comisión de la verdad. Recuperado de http://www.alfonsozambrano.com/comision_verdad/cdv10conclusiones.pdf

\section{Referencias en prensa}

El Universo (10 de octubre de 2009). "La inseguridad de Guayaquil enfrentó a Correa y Nebot”. Recuperado de http://www.eluniverso. com/2009/10/10/1/1355/inseguridad-guayaquil-enfrento-correanebot.html

El Telégrafo. (11 de enero de 2013). El déficit de viviendas fiscales para policías se acabará en 2 años. Recuperado de http://www.telegrafo. com.ec/justicia/item/el-deficit-de-viviendas-fiscales-para-policiasse-acabara-en-2-anos.html 
EL Telégrafo. (18 de noviembre de 2013b). La depuración inicia en el reclutamiento. Recuperado de http://www.telegrafo.com.ec/justicia/ item/la-depuracion-inicia-en-el-reclutamiento.html

Hoy. (17 de enero de 2011). Las diezpreguntas del Referendo y Consulta. Recuperado de http:/ / www.hoy.com.ec/noticias-ecuador/las-diez-preguntasdel-referendo-y-consulta-453579.html

Hoy. (16 de junio de 2014). Más de 40 mil policías serán evaluados hasta 2017. Recuperado de http://www.hoy.com.ec/noticias-ecuador/masde-40-mil-policias-seran-evaluados-hasta-2017-608398.html 
